\title{
Estágios de desenvolvimento econômico e políticas públicas de empreendedorismo e de micro, pequenas e médias empresas (MPMEs) em perspectiva comparada: os casos do Brasil, do Canadá, do Chile, da Irlanda e da Itália'
}

\author{
Gilberto Sarfati \\ Escola de Administração de Empresas de São Paulo (EAESP/FGV)
}

\begin{abstract}
Esta pesquisa explora em perspectiva comparada as políticas públicas de empreendedorismo e Micro, Pequenas e Médias Empresas (MPMEs) no Brasil, no Canadá, no Chile e na Itália. A hipótese fundamental é que economias no estágio de inovação tendem a desenvolver mais políticas de empreendedorismo do que as de países no estágio da eficiência. Da mesma forma, países no estágio de inovação tendem a usar menos instrumentos de políticas de MPMEs do que países em estágio de eficiência, quase sempre para incentivar grupos, setores ou regiões em específico. O artigo contribui com a literatura de empreendedorismo ao analisar na prática a convergência/divergência das escolhas de política pública e estágio de desenvolvimento.
\end{abstract}

Palavras-chave: política pública; empreendedorismo; micro, pequenas e médias empresas.

Etapas de desarrollo económico y políticas públicas para emprendimiento y micro, pequeñas y medianas empresas (MIPYMEs) en una perspectiva comparada: los casos de Brasil, Canadá, Chile, Irlanda y Italia

Esta investigación explora en una perspectiva comparada las políticas públicas para emprendimiento y las micro, pequeñas y medianas empresas (MIPYMES) en Brasil, Canadá, Chile e Italia. La hipótesis subyacente es que las economías en la etapa de innovación tienden a desarrollar más políticas de emprendimientos que los países en la etapa de la eficiencia. Del mismo modo, en los países en etapa de innovación tienden a utilizar menos instrumentos de MIPYMES que países en la etapa de innovación para animar a los grupos, regiones o sectores específicos. El trabajo contribuye a la literatura sobre emprendimiento por analizar la convergencia / divergencia de opciones de política pública y la etapa de desarrollo.

Palabras clave: política pública; emprendimiento; las empresas micro, pequeñas y medianas.

Artigo recebido em 22 set. 2011 e aceito em 14 nov. 2012.

${ }^{1} \mathrm{O}$ autor deseja agradecer o apoio para a realização desta pesquisa concedido pelo GVPesquisa. O autor agradece também o apoio da Secretaria de Assuntos Estratégicos e ao Programa das Nações Unidas para o Desenvolvimento (Pnud) no projeto que originou este artigo, sobre Cenários Prospectivos Internacionais de Empreendedorismo. 
Stages of economic development and public policies for entrepreneurship and for micro, small, and medium enterprises (MSMEs) from a comparative perspective: the cases of Brazil, Canada, Chile, Ireland, and Italy

This study applies a comparative perspective to the public policies for entrepreneurs and Micro, Small, and Medium Enterprises (MSMEs) in Brazil, Canada, Chile, and Ireland. The fundamental hypothesis is that economies in the innovation stage of economic development tend to develop more policies for entrepreneurship than countries in the efficiency stage. Similarly, countries in the innovation stage tend to apply fewer policies to MSMEs than countries in the efficiency stage to encourage development in specific groups, sectors, or regions. This article contributes to the literature on entrepreneurship by analyzing the convergence and divergence of the public policy choices at different stages of economic development.

KEY WORDs: public policy; entrepreneurship; micro, small and medium enterprises.

\section{Introdução}

As micro, pequenas e médias empresas (MPMEs) representam mais de $98 \%$ do total das empresas nas economias desenvolvidas, mais de $60 \%$ do emprego na economia e cerca de $50 \%$ do Produto Interno Bruto (PIB). Por outro lado, nas economias menos desenvolvidas as MPMEs empregam pouco mais de $30 \%$ da força de trabalho e representam pouco mais de $10 \%$ do PIB (IFC, 2007).

As diferenças extremas entre as economias demonstram a importância que a atividade empreendedora pode ter no desenvolvimento econômico. Esta pesquisa explora, em perspectiva comparada, a relação entre estágio de desenvolvimento econômico e as escolhas de políticas públicas para o empreendedorismo e as MPMEs no Brasil, no Canadá, no Chile, na Irlanda e na Itália. A hipótese fundamental é que economias no estágio de inovação tendem a desenvolver mais políticas de empreendedorismo do que países no estágio da eficiência. Da mesma forma, países no estágio de inovação tendem a usar menos instrumentos de políticas de MPMEs do que países em estágio de eficiência, quase sempre para incentivar grupos, setores ou regiões em específico.

Primeiro, o artigo discute o referencial teórico da relação entre empreendedorismo e desenvolvimento econômico; em seguida, explora as políticas públicas de empreendedorismo e MPMEs nos países selecionados relacionando as mesmas com o estágio de desenvolvimento. O artigo conclui que as escolhas de política pública são compatíveis com o estágio de desenvolvimento econômico em todos os casos, menos o da Itália. A implicação principal é que países como Brasil e Chile estão, no momento, focados em diminuir as barreiras para a atividade das MPMEs enquanto países como Irlanda e Canadá, já tendo superado esta fase, estão focados na promoção do empreendedorismo inovador de alto impacto, o que deve contribuir para a posição desses países no estágio de inovação. Já no caso da Itália, a ausência de políticas de empreendedorismo implica perda de competitividade no estágio de inovação.

O artigo contribui com a literatura de empreendedorismo explorando como países de diferentes regiões, tamanho e estágio de desenvolvimento escolhem apoiar o empreendedorismo e as MPMEs. 


\section{Referencial teórico}

Há a necessidade de se criar políticas públicas de fomento ao empreendedorismo? Dentro deste debate algumas questões são consideradas chaves:

- O papel do empreendedorismo no desenvolvimento econômico.

- A necessidade e o escopo de políticas públicas.

O primeiro debate concentra-se no papel das MPMEs na geração de empregos, crescimento econômico, diminuição das desigualdades sociais e inovação. Esta hipótese schumpeteriana tem sido estudada por diversos autores (Holtz-Eakin e Kao, 2003; Newberry, 2006; Luetkenhorst, 2004; Raynard e Forstater, 2002), que apontam para uma correlação positiva entre a incidência da atividade empreendedora e o crescimento da economia, aumento do emprego, diminuição da desigualdade social, desenvolvimento da cadeia produtiva das empresas multinacionais (EMNs) e desenvolvimento de iniciativas de sustentabilidade.

Por outro lado, Van Stel, Carree e Thurik (2005), em um estudo de 36 países, notam que a atividade empreendedora tem efeito positivo em economias desenvolvidas e negativo em países pobres. Na mesma linha, diversos trabalhos (Beck, Demirguç-Kunt e Levine, 2005; Audrestsch e Keilbach, 2004; Wennekers e Thurik, 1999) demonstram que não há evidências conclusivas da relação entre atividade empreendedora e crescimento econômico.

Entretanto, novas evidências (Henrekson e Johansson, 2008) apontam que algumas empresas de crescimento acelerado, também chamadas de gazelas, têm um grande impacto na geração de empregos e crescimento econômico. Como indicam Henrekson e Stenkula (2009), as diferenças nas pesquisas podem ser resultado das diferenças entre empreendedorismo e o trabalhador por conta própria, também conhecido como empreendedor estilo de vida.

O trabalhador por conta própria ou o tradicional pequeno empresário (estilo de vida) não pode ser confundido com o empreendedor de alto impacto, pois o primeiro constitui uma empresa para satisfazer minimamente suas necessidades, o que logicamente gera empregos mediante, por exemplo, atividades como cabeleireiros, padarias, confecções etc. Por outro lado, o segundo tem uma atividade de alto crescimento que aceleradamente gera empregos e valor econômico.

Para OECD (2011), empresas de alto crescimento podem ser definidas como empresas que geraram um aumento no número de empregos maior que $20 \%$ ao ano em um período de três anos, considerando um mínimo de 10 empregados no início do período observado. As empresas chamadas "gazelas" seriam um subtipo das empresas de alto crescimento, tendo menos de cinco anos de vida e apresentando em um período de três anos crescimento no número de empregados ou receita de ao menos $20 \%$ ao ano.

Esta diferença nos leva à segunda questão, a de necessidade e escopo de políticas públicas. É preciso diferenciar políticas públicas de empreendedorismo de políticas públicas para as MPMEs. Políticas voltadas para as MPMEs envolvem programas que apoiam o empreendedor estilo de vida, o que pode ser justificado por diversas razões, como efeitos macroeconômicos positivos de criação de empregos ou mesmo compensação por efeitos microeconômicos cola- 
terais de economias de escala. Por outro lado, políticas de empreendedorismo visam fomentar empreendedores (indivíduos) altamente inovadores que possam gerar um alto impacto no crescimento econômico movendo a economia para produtos e serviços com maior valor agregado (Henrekson e Stenkula, 2009).

A visão cética sobre políticas públicas aponta que empresas de grande porte são mais capazes de ter ganhos de escala e de levantar os fundos para pesquisa e desenvolvimento, além de prover mais empregos estáveis. Afora isso, há um questionamento sobre a eficiência de atividades de promoção, já que empresas grandes poderiam gerar mais efeitos positivos sobre o crescimento econômico (Beck, Demirguç-Kunt e Levine, 2005).

Podemos relacionar as diferenças sobre as visões de política pública com os estágios de desenvolvimento econômico sugeridos por Porter e colaboradores (2002:1) estágio movido por fatores de produção, 2) estágio movido pela eficiência, 3) estágio movido pela inovação. O estágio de fatores é marcado por uma economia agrícola e empreendedores estilo de vida. Nesse estágio o país é caracterizado pela produção de commodities e produtos com baixo valor agregado e grande parte das empresas são manufatureiras e pequenas de serviço. Já no estágio de eficiência o país tem de explorar economias de escala, o que favorece a concentração industrial. Finalmente, no estágio movido a inovação, a economia passa a ser fortemente caracterizada por atividades intensivas em conhecimento, o que fortemente caracteriza a atividade empreendedora.

O gráfico 1 mostra a relação entre a atividade empreendedora e as fases de desenvolvimento econômico de Porter.

Gráfico 1

Relação entre empreendedorismo e desenvolvimento econômico e acordo com estágio de desenvolvimento de Porter (1998)

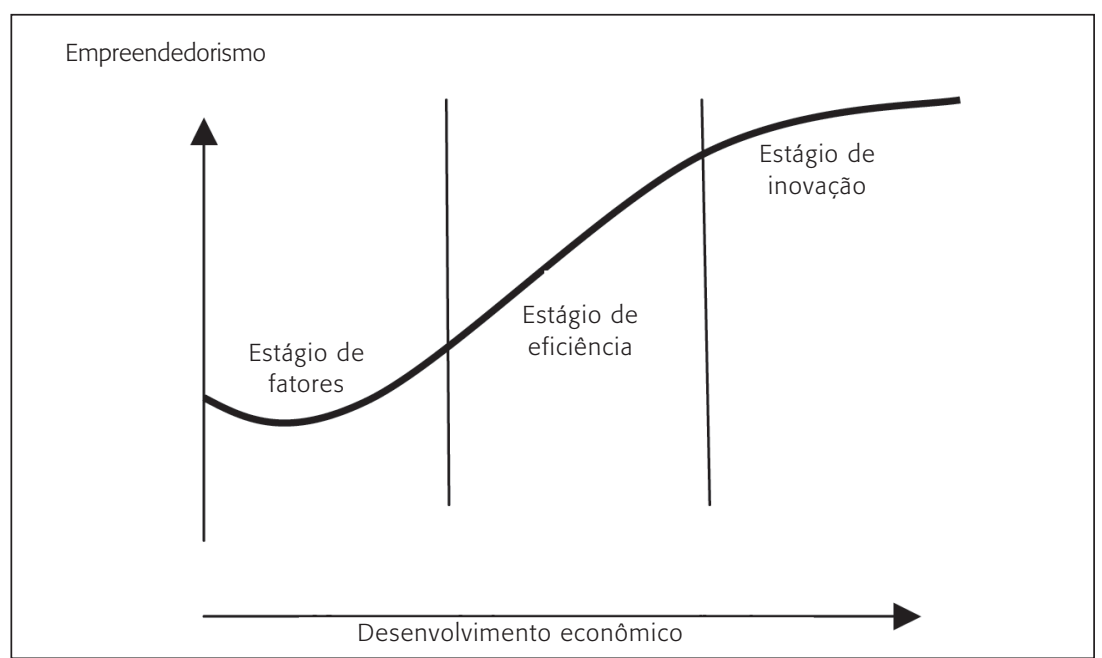

Fonte: Ács e Szerb (2009:351). 
O Global Entrepreneurship Monitor (GEM) 2009 deixa claro que a preocupação básica na fase de fatores é o provimento de serviços básicos de infraestrutura como educação, saúde etc. À medida que o país ganha estabilidade econômica e infraestrutura, passa a se notar uma relação positiva entre crescimento econômico e atividade empreendedora (Lundstrom e Stevenson, 2005).

Ács e Szerb (2009), com base em dados brutos do GEM, desenvolveram recentemente o Índice Global de Empreendedorismo (Geindex), que é uma composição de subindicadores relativos a atividade, atitude e aspiração empreendedora. Além disso, o índice considera que esses componentes são uma função das condições institucionais de cada país.

Os autores, analisando os resultados para os 64 países da amostra, indicam que um conjunto de fatores essencialmente institucionais é fundamental para a transição de uma economia de fatores para uma de eficiência. Fatores como: melhora no Easy Doing Business Index (EDBI), liberdade econômica, uso de internet, corrupção e desenvolvimento humano costumam ser superiores entre países de eficiência em comparação a economias de fatores. Já os fatores fundamentais para a transição para economia de inovação passam por desenvolvimento da educação superior, disponibilidade das últimas tecnologias, ambiente inovativo, $\mathrm{P} \& \mathrm{D}$, venture capital e diminuição da percepção do risco de falhar.

Com base na recente literatura (OECD, 2010; Henrekson e Stenkula, 2009; Hall e Sobel, 2006; Murdock, 2009; Lundstrom e Stevenson, 2001; Storey, 2008), vemos que os principais condicionantes que afetam a atividade empreendedora são:

v Mudanças demográficas: movimentos migratórios, idade etc.

จ Mudanças sociais: consciência ambiental, nível de educação etc.

- Mudanças econômicas: estabilidade macroeconômica, relações comerciais com outros países etc.

จ Mudanças regulatórias: oportunidades advindas em mudanças de regulação em setores específicos, incluindo regulações definidas em contextos multilaterais.

v Mudanças tecnológicas: emergência de novas tecnologias.

Estes condicionantes afetam o desenvolvimento de políticas públicas de empreendedorismo e de MPMEs. Essas políticas podem ser classificadas em políticas regulatórias e políticas de estímulo, conforme a figura 1:

As políticas regulatórias que afetam as MPMEs e o empreendedorismo são:

- Regras de entrada e saída de negócios

v Regras trabalhistas e sociais

Regras de propriedade

จ Regras tributárias

จ Regras de propriedade intelectual 
$\checkmark$ Regras de falência

Regras que afetem a liquidez e disponibilidade de capital (incluindo taxas de juro e acesso a financiamento)

Figura 1

Condições que afetam a atividade empreendedora e opções de política pública

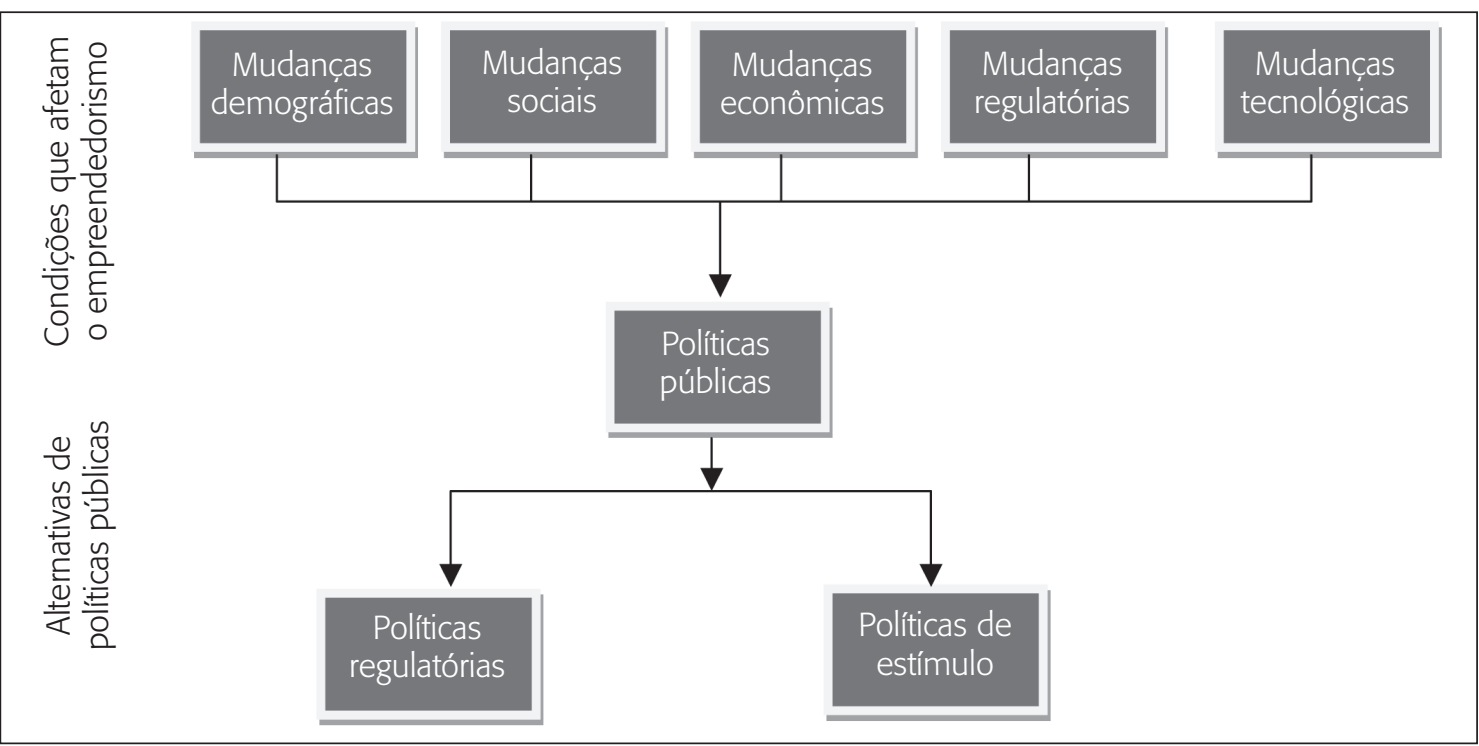

Fonte: Elaboração própria.

Já as políticas de estímulo estão relacionadas a ações que diretamente promovem a atividade empreendedora. Essas atividades podem ser classificadas em:

v Promoção de cultura e educação empreendedora

、 Desenvolvimento de indústria de incubadoras e venture-capital

、 Programas de promoção à inovação (pesquisa e desenvolvimento)

v Programas de fomento à internacionalização

Todas essas políticas podem ainda ser analisadas em diversas dimensões verticais tais como:

จ Política nacional ou regional

$\checkmark$ Focadas em setores específicos (como biotecnologia)

、 Grupos de indivíduos (negros, mulheres, jovens) 
As políticas regulatórias tendem a afetar de forma indiscriminada as MPMEs e o empreendedorismo, enquanto as de estímulo tendem a fomentar o surgimento de empreendedores de alto impacto. Entretanto, o crescimento no número de empreendedores de alto impacto está condicionado a um ambiente regulatório mais favorável.

Lundstrom e Stevenson (2001) sugerem que no desenvolvimento de políticas públicas há (ou ao menos deveria haver) uma intersecção entre políticas de empreendedorismo, voltadas para a criação do empreendimento, e o período pós start up com políticas voltadas às MPMEs que já teriam superado o período crítico de 42 meses.

\section{Figura 2}

Interconexão entre políticas de empreendedorismo e de MPMEs

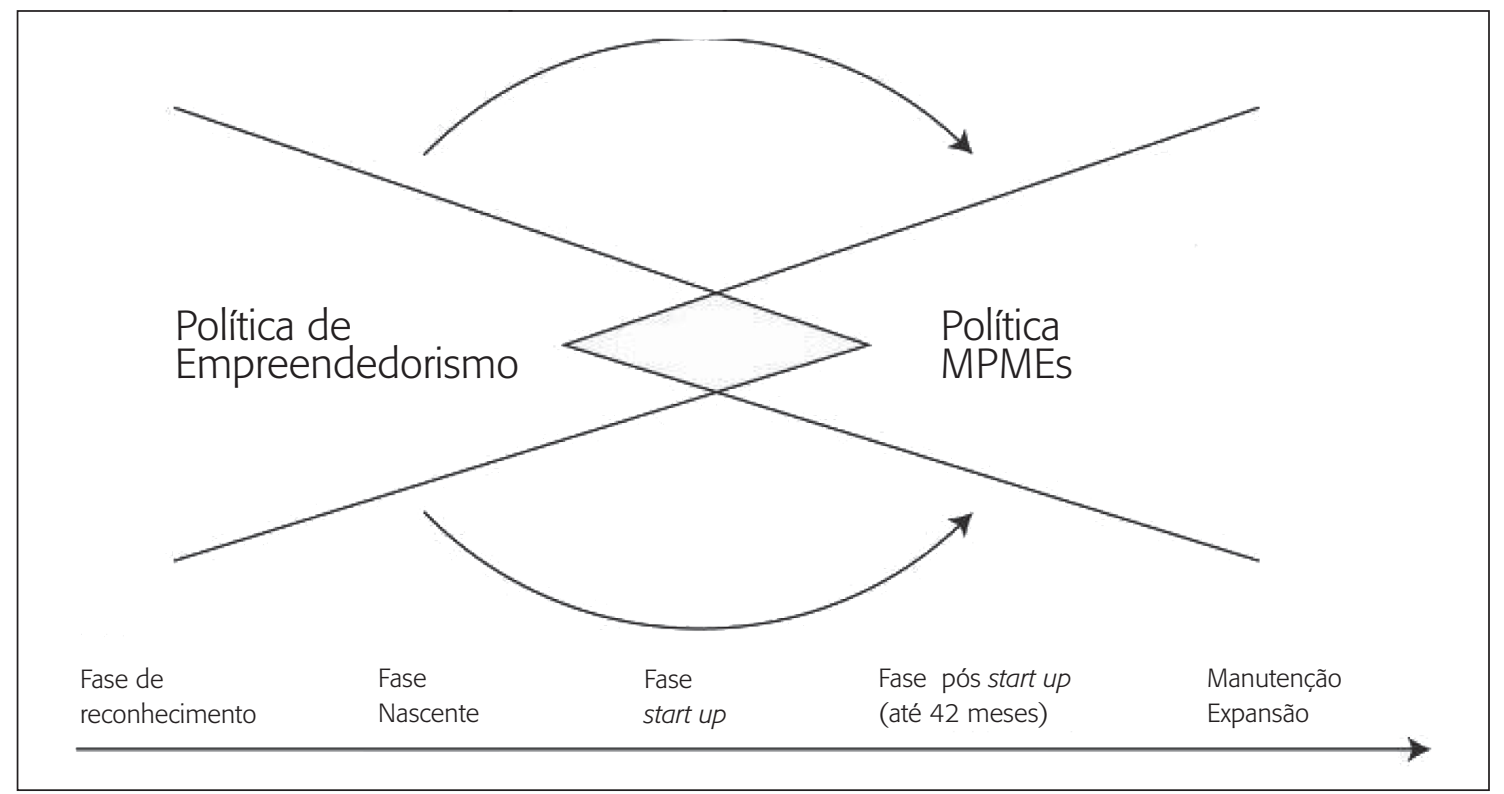

Fonte: Lundstrom e Stevenson (2001).

\section{Metodologia}

A vantagem da utilização do estudo de caso comparado com o objetivo desta pesquisa é de possibilitar a avaliação de fraquezas e fortalezas das políticas públicas dos países avaliados. A pesquisa foi conduzida com dados e informações retirados de diversas fontes oficiais multilaterais e governamentais, além de resultados de pesquisas conduzidas por instituições independentes. Foram conduzidos trabalhos de campo em cada um dos cinco países onde foram realizadas 40 entrevistas com autoridades públicas e acadêmicas para complementar o diagnóstico em cada um dos países selecionados. 
Para esta pesquisa foram selecionados cinco países, que atenderam a critérios de representatividade regional, porte da economia e desenvolvimento da atividade empreendedora. Os países selecionados foram Brasil, Canadá, Chile, Irlanda e Itália. Os cinco países cobrem diferentes regiões do globo, portes de economia e estágios de desenvolvimento.

As entrevistas semiestruturadas ocorreram no período de agosto a outubro de 2010 . Os objetivos das entrevistas eram confrontar as informações levantadas nas pesquisas secundárias com as informações e percepções dos agentes das políticas e outros stakeholders. Dessa forma, as entrevistas proveram acuidade no mapeamento de políticas públicas bem como profundidade na compreensão analítica dos distintos programas. Instituições entrevistadas incluem, no Brasil, Secretaria de Assuntos Estratégicos (SAE), Ministério do Desenvolvimento, Indústria e Comércio (MDIC), Serviço Brasileiro de Apoio às Micro e Pequenas Empresas (Sebrae); no Canadá, Ministério da Indústria e Conselho Nacional de Pesquisa (National Research Council - NRC); no Chile, Ministério da Economia, Corporação de Fomento a Produção (Corfo) e Serviço de Cooperação Técnica (Sercotec); na Itália, Ministério do Desenvolvimento e Promoção Industrial e Confederação Nacional da Pequena e Média Empresa (Confap); e, na Irlanda, Enterprise Ireland, Forfás e Ministério das Empresas, Comércio e Inovação. Professores e especialistas nesses países também foram entrevistados para a obtenção de visões fora do governo.

As políticas públicas desses países foram classificadas entre regulatórias e de estímulo. Dentro das políticas de estímulo foram analisadas as ações em nível nacional e regional de promoção de cultura e educação empreendedora; promoção à inovação (pesquisa e desenvolvimento) e programas de fomento à internacionalização.

Embora o desenvolvimento de indústria de incubadoras e venture capital faça parte da política de estímulo ao empreendedorismo, ela não será apresentada aqui, dada a dinâmica específica deste setor. Foram levantadas também iniciativas que afetem grupos específicos, como minorias. Já em relação a políticas regulatórias, foram mapeadas as ações do governo que afetam como um todo as MPMEs.

\section{As políticas públicas de estímulo e regulação do empreendedorismo e das MPMEs no Brasil, no Canadá, no Chile, na Itália e na Irlanda}

\subsection{Brasil}

No Brasil não existe uma nomenclatura única para a classificação do porte de uma empresa. De acordo com a lei geral das micro e pequenas empresas (Lei Complementar no 123/2006), uma microempresa deve ter faturamento anual de até cerca de US\$ 150 mil e a de pequeno porte cerca de US\$1,5 milhão. ${ }^{2}$ Já o Sebrae classifica o porte das empresas de acordo com

\footnotetext{
${ }^{2}$ Conversão do real ao dólar americano com base em março de 2011.
} 
número de funcionários, sendo menos de nove, micro, de 10 a 49, pequena, de 50 a 99, média e acima de 100, grande porte.

De forma geral, as políticas públicas no Brasil historicamente não priorizaram as MPMEs, seja pelos períodos de substituição de industrialização e substituição das importações das décadas de 1950 a 1970, passando pela crise econômica da década de 1980 até o período de neoliberalismo econômico da primeira metade da década de 1990.

Neste período e, ainda hoje, o principal ator de incentivo as MPMEs é o Sebrae, ${ }^{3}$ que foi fundado em 1972 como uma entidade privada de interesse público. O conselho superior da organização é constituído de 13 instituições governamentais e não governamentais. Mais de $70 \%$ da receita da organização vêm das contribuições obrigatórias que as empresas de médio e grande porte devem pagar com uma alíquota de 0,3\% incidente sobre o salário do trabalhador. Ou seja, embora a entidade não seja parte do governo, o mesmo tem um enorme peso no direcionamento estratégico da entidade.

Hoje, o Sebrae está presente nos 27 estados da federação com 336 postos de atendimento próprio e 452 via parceiros, contando com 4,5 mil funcionários e 12 mil consultores externos devidamente capacitados pela entidade para atender as micro e pequenas empresas. A entidade apoia as empresas com cursos, palestras, treinamentos, promoção de feiras de negócios, publicações e consultoria.

Há dois grandes eixos de mudanças de tratamento da política pública em relação às MPMEs a partir da segunda metade da década de 1990. O primeiro, no nível regulatório, a Lei no 9.317/1996, conhecida como Lei Federal da Simples, que ordena tratamento tributário diferenciado às micro e pequenas empresas, e a Lei no 9.841/1999, conhecida como Estatuto da Micro e Pequena Empresa, regulando aspectos como relações de trabalho, linhas de crédito e criando o Fórum Permanente das Micro e Pequenas Empresas dentro da estrutura do Ministério do Desenvolvimento, Indústria e Comércio Exterior (MDIC).

Ambas as leis foram revogadas pela Lei Complementar no $=123 / 2006$, que instituiu o Estatuto Nacional da Microempresa e da Empresa de Pequeno Porte e estabeleceu normas gerais relativas ao tratamento diferenciado e favorecido a ser dispensado às microempresas e empresas de pequeno porte no âmbito dos poderes da União, dos estados, do Distrito Federal e dos municípios.

Outra lei que cabe mencionar é a Lei no 11.196/2005, conhecida como Lei do Bem, que trata de incentivos fiscais à inovação que têm sido aproveitados por empresas de médio e grande porte, mas o governo federal estuda mecanismos para estender o benefício a pequenas empresas.

O segundo eixo de mudança na importância das MPMEs nas políticas públicas brasileiras é a instituição da Política Industrial, Tecnológica e de Comércio Exterior (PITCE) em 2003. Dentro dessa política, as MPMEs passam a ser prioridade das ações de política pública por meio dos Arranjos Produtivos Locais (APLs). Conforme definição do MDIC, ${ }^{4}$ os APLs são

\footnotetext{
${ }^{3}$ Informações disponíveis no site da entidade: <www.sebrae.com.br>. Acesso em: 24 jul. 2011.

${ }^{4}$ Disponível em: <www.mdic.gov.br/sitio/interna/interna.php?area=2\&menu=300>. Acesso em: 24 jul. 2011.
} 
aglomerações de empresas, localizadas em um mesmo território, que apresentam especialização produtiva e mantêm vínculos de articulação, interação, cooperação e aprendizagem entre si e com outros atores locais, tais como: governo, associações empresariais, instituições de crédito, ensino e pesquisa.

Em outras palavras os APLs são clusters produtivos.

Em torno da nova PITCE, outras agências governamentais passaram a apoiar as MPMEs via especialmente APLs; esse é o caso do Banco Nacional de Desenvolvimento Econômico e Social (BNDES), Agência Brasileira de Promoção de Exportação e Investimentos (Apex), o Ministério da Ciência e Tecnologia e a Financiadora de Estudos e Projetos (Finep).

O último mapeamento do Grupo de Trabalho Permanente para APLs subordinado ao MDIC, em 2005, apontou para a existência de 957 APLs espalhados pelo país, dos quais 267 são considerados prioritários para o governo. ${ }^{5}$

Apesar do papel do MDIC, não há atividade coordenada de apoio aos APLs e, portanto, há uma sobreposição de programas nos níveis federais, estaduais e municipais. No estado de São Paulo, por exemplo, o governo estadual tem um programa de apoio específico, desvinculado de iniciativas federais, a 15 APLs (dos 24 reconhecidos oficialmente pelo governo) em parceria com o Banco Interamericano de Desenvolvimento (BID). ${ }^{6}$

Do ponto de vista de financiamento, há diversos programas em níveis federal, estadual e municipal que beneficiam as MPMEs, como o Cartão BNDES, que é uma linha de crédito, repassado por bancos comerciais, para compra de produtos e serviços. Outro exemplo é a Finep Inova Brasil, que é um programa de financiamento da Finep com encargos reduzidos para a realização de projetos de pesquisa, desenvolvimento e inovação nas empresas. Na outra ponta, no nível municipal, a Prefeitura de Ribeirão Preto, por exemplo, tem um programa de financiamento voltado para microempreendedores da cidade chamado Banco do Povo.

Embora não haja programas de fomento a uma cultura empreendedora no nível federal (à exceção dos projetos de fomento à indústria de venture capital vinculados à Finep), há iniciativas municipais positivas como a da cidade de São José dos Campos, que na década passada incluiu o empreendedorismo dentro das diretrizes da educação no ensino fundamental na rede municipal.

Do ponto de vista regulatório, é preciso notar que, apesar dos avanços da Lei nº 123/2006, abrir, manter e fechar uma empresa no Brasil é bastante complexo em face das demandas que frequentemente se modificam dos vários níveis de governo municipal, estadual e federal, não configurando ainda um ambiente adequado para a execução da atividade empreendedora.

\footnotetext{
${ }^{5}$ Disponível em: <www.mdic.gov.br/portalmdic/sitio/interna/interna.php?area=2\&menu=2985>. Acesso em: 25 jul. 2011.

${ }^{6}$ Disponível em: <www.desenvolvimento.sp.gov.br/drt/apls/>. Acesso em: 25 jul. 2011.
} 


\subsection{Canadá}

De acordo com a nomenclatura usada pelo Ministério da Indústria do Canadá, o porte da empresa é classificado em função do número de empregados, sendo até quatro para micros, entre cinco e 99 para pequenas e 100 até 499 empregados para as médias. Embora não faça parte da classificação oficial, é possível indicar, segundo dados das Estatísticas do Canadá, que cerca de 90\% das MPMEs faturam menos de US\$ 500 mil por ano.

Lundstrom e Stevenson (2001) notam que, na década de 1960, a política industrial canadense priorizou o desenvolvimento de P\&D industrial. Já na década de 1970 a prioridade passou a ser a assistência para que grandes empresas pudessem competir internacionalmente. Parte das políticas públicas incluiu medidas para fomentar o desenvolvimento regional mediante atração de investimentos e instalação de manufaturas em zonas com alta incidência de desemprego.

Na década de 1980, o objetivo de diminuição das disparidades regionais aprofundou-se. Em 1982, foi criado o Escritório de Empreendedorismo e Pequenos Negócios (Entrepreneurship and Small Business Office) ligado ao Departamento de Expansão Industrial Regional, encarregado de analisar a questão das pequenas empresas no país. Esse departamento implementou o Programa de Imigração de Negócios (Business Immigration Program), que simplificou os procedimentos de imigração para investidores e empreendedores que buscassem constituir empresas no país (Lundstrom e Stevenson, 2001; Riverin et al., 2003).

Desde 1982, o governo canadense passou a atribuir importância estratégica às MPMEs como fonte de geração de empregos, inovação e desenvolvimento econômico. O governo estabeleceu um Ministério do Empreendedorismo que, após ampla pesquisa, implementou a primeira Política Nacional de Empreendedorismo em conjunto com o financiamento de cinco anos para o Instituto Nacional de Desenvolvimento de Empreendedorismo (National Entrepreneurship Development Institute - Nedi). Em 1993, o Nedi e o status de ministro de Estado do seu dirigente foram eliminados (Lundstrom e Stevenson, 2001).

Em 1993, o governo introduziu o conceito de "janela de serviços" por meio da criação do Centro de Serviços de Negócios do Canadá (Canada Business Service Center) (Lundstrom e Stevenson, 2001), atual Serviços de Negócios para Empreendedores do Canadá (Canada Business Services for Entrepreneurs). Esses centros simplificam o acesso às informações críticas para começar e gerir negócios, além de proverem informações de acesso a programas de fomento às MPMEs. Esses programas foram introduzidos em todas as províncias canadenses, visando diminuir as barreiras ao empreendedorismo.

A partir de 1994, em função de restrições orçamentárias, o governo canadense passou a focar o apoio do Estado essencialmente ao empreendedor gazela. Entretanto, a simplificação regulatória e tributária, ou seja, a remoção de barreiras institucionais ajudou a fomentar o empreendedorismo em todos os níveis. Na verdade, desde esse período, as iniciativas de promoção ao empreendedorismo têm sido extremamente fragmentadas.

Hoje, a autoridade de fomento ao empreendedorismo está basicamente nas mãos da Indústria Canadá (Industry Canada - IC), que administra uma política industrial integrada, orientada para uma economia de conhecimento. 
A grande maioria dos programas de estímulo no país está agrupada no chamado Serviços de Negócios para Empreendedores do Canadá. Há um centro do programa em cada província, proporcionando diversos pontos de acesso aos serviços. Além de ter como objetivo a consolidação de informações de negócios, a plataforma visa também reduzir a complexidade de lidar com vários níveis de governo (federal, da província e do município), permitindo que o empreendedor tome decisões bem pautadas em uma economia global. O Serviços de Negócios para Empreendedores do Canadá é um acordo de colaboração entre departamentos e agências federais, governos provinciais e territoriais e entidades sem fins lucrativos.

Dentro das políticas de estímulo, o NRC é uma instituição subordinada ao IC, que tem como objetivo auxiliar o país na área de P\&D, bem como na inovação e comercialização, tomando medidas para: desenvolver soluções para as áreas de saúde e bem-estar, energia sustentável e meio ambiente. No suporte específico às MPMEs, a NRC fornece assistência técnica e financeira àquelas com potencial para liderar uma nova área de tecnologia, dando acesso a pesquisa de ponta, redes e equipamentos especializados. Há auxílio ao desenvolvimento de negócios e apoio à comercialização, bem como ao desenvolvimento de novas tecnologias e na preparação para o mercado.

O Canadá vem buscando promover a formação de clusters regionais de alta tecnologia (são 11 no momento), através do NRC, com cerca de 4.300 funcionários distribuídos em 19 agências espalhadas pelo país, as quais fomentam o P\&D principalmente através das universidades em projetos com alto potencial de spin-off. O desenvolvimento destes clusters cumpre também o objetivo do governo de diminuir as desigualdades regionais por meio do desenvolvimento de atividades de alto valor agregado. Para isso, a parceria com as universidades é fundamental para que, de fato, haja centros de educação e pesquisa de excelência.

Em relação às políticas regulatórias, pode-se afirmar que abrir, manter e fechar um negócio no Canadá é relativamente simples. De acordo com Nadeem (2010), os custos de produção do país são competitivos em relação a outros países do G7, particularmente em relação aos Estados Unidos. Além disso, as recentes reformas fiscais tornaram o país ainda mais atrativo, reforçado por seus custos trabalhistas baixos e infraestrutura adequada.

\subsection{Chile}

Segundo a classificação do governo chileno as microempresas são aquelas que faturam até cerca de US\$106.700 por ano, as pequenas, entre este valor e cerca de US\$1,11 milhão, e as médias empresas, até US\$ 4,45 milhões.

Historicamente, a economia chilena sempre esteve ligada à produção de commodities, desde o salitre no século XIX, passando pelo cobre e outros produtos agrícolas no século passado e neste início de século XXI.

Grande parte das tentativas de industrialização no país passa pela história da Corporação de Fomento a Produção (Corporación de Fomento de la Produción - Corfo), que foi fundada em 1939 com o propósito de fomentar o desenvolvimento econômico no país. 
A agência foi fundada logo após o grande terremoto de 1938 e, por meio de mecanismos de aporte de capital, política de créditos e intervenções diretas, buscou direcionar o crescimento econômico.

Já no governo Allende, a Corfo foi um instrumento do processo de estatização, tendo chegado a controlar 500 unidades produtivas até 1973, quando, após a tomada do poder pelos militares, o rumo contrário, das privatizações, foi tomado. Hoje, a Corfo continua usando os instrumentos de aporte de capital e financiamento, além de outros mecanismos como treinamento, todos voltados ao desenvolvimento industrial.

A Corfo não se redirecionou completamente para o fomento do empreendedorismo e as MPMEs. Entretanto, desde a redemocratização do país, os governos passaram a dar mais atenção ao empreendedorismo, ora por razões sociais, ora por considerarem fundamental o desenvolvimento de empresas que possam diminuir a dependência do país em relação às commodities.

Segundo o Ministério da Economia do Chile, existem hoje no país mais de 100 instrumentos de fomento, de uma série de naturezas (Dini e Stumpo, 2002). A aplicação desses instrumentos se dá basicamente por órgãos governamentais, representados principalmente pelas agências de fomento. No entanto, é notável que uma série de políticas seja implementada com o auxílio da iniciativa privada, que terceiriza serviços das repartições públicas ou oferece serviços próprios, ainda que estimulados pela figura estatal, caso frequente nas políticas de cunho financeiro.

No Chile, não há uma entidade única que centraliza as políticas públicas de amparo à atividade empreendedora. O capital governamental destinado para tal fim é passado aos ministérios que por sua vez o distribuem entre os diversos órgãos sob sua tutela, que constituem, nos diferentes âmbitos de atuação, mais de 20 instituições de fomento responsáveis pela aplicação do capital estatal (Ferraro e Stumpo, 2010).

Desde que começaram a surgir, na década de 1990, os programas de apoio a MPMEs e ao empreendedor no Chile referem-se ao apoio a capacitação de recursos humanos, assistência técnica, fomento ao cooperativismo, acesso ao crédito, promoção exportadora, apoio a inovação e transferência tecnológica, e apoio à retomada produtiva em áreas em dificuldades.

Nos dias de hoje, todas essas continuam sendo esferas de atuação dos programas de incentivos. No entanto, outras foram sendo incorporadas, como a promoção de investimentos, o apoio ao empreendimento e à incubação de novos negócios, o auxílio a certificação e a promoção de redes empresariais territoriais (Ferraro e Stumpo, 2010).

Do ponto de vista de política regulatória, o país tem feito um grande esforço para simplificar a atividade das MPMEs. Um exemplo recente disso é a Lei no 20.416 - Estatuto Empresas de Pequeno Porte (EMT). O principal componente da lei é a exigência de que o legislador internalize o conceito de custo-efetividade ao estabelecer instrumentos reguladores que atinjam as empresas de pequeno porte. Em outras palavras, uma das provisões mais importantes do estatuto é a instituição da avaliação de impacto regulatório, ou seja, a obrigatoriedade de que toda lei, regulamento ou norma identifique o seu impacto junto às MPMEs. 


\subsection{Itália}

Seguindo a nomenclatura da Comissão Europeia, as microempresas são aquelas com menos de 10 empregados e faturamento inferior a U\$2 milhões, as pequenas empresas têm menos de 50 empregados e faturamento anual de até $\mathrm{U} \$ 10$ milhões, e as médias, até 250 empregados e faturamento anual de U\$50 milhões.

A indústria italiana tem como principal característica a divisão regional em distritos industriais. Essa forma de organização se iniciou nos anos 1970 com o desenvolvimento da região central do país, provocada principalmente pela crise do noroeste italiano, uma vez que surgiram várias pequenas empresas nessa época. A fim de produzir de maneira mais eficiente, as pequenas empresas regionais passaram a se reunir em cadeias produtivas e iniciaram assim a formação de clusters chamados distritos industriais (distriti industriale).

Embora o desenvolvimento industrial do país tenha sido essencialmente regional, as regiões italianas não são autônomas, ou seja, essencialmente são unidades administrativas que descentralizam a máquina estatal. Entre as 20 regiões do país, cinco são exceção a esse modelo, possuindo um estatuto especial que garante a autonomia regional: as ilhas de Sardenha e Sicília; o Trentino-Alto Adige (no norte, com uma considerável minoria de origem germânica), Vale de Aosta (com minoria de origem francesa) e Friul-Veneza Júlia (com minoria de origem eslovena). As outras regiões vêm ganhando autonomia em relação ao governo central, mas política e economicamente ainda são totalmente dependentes do governo central.

No início da industrialização, os distritos industriais mostraram-se muito efetivos, já que as MPMEs se especializam em uma pequena parte da cadeia produtiva; portanto, há foco e controle de recursos e cada companhia somente exerce a função que sabe desempenhar bem (core competencies), e a cooperação entre as diversas empresas permite a produção de bens com alta qualidade, que não é possível de se obter com a produção de apenas uma empresa regional sozinha.

A formação de clusters alavancou a economia italiana até os anos 1990, quando a economia mundial começou a passar por um processo de transformação que mudou a natureza dos produtos, os processos de produção e a distribuição dos bens e serviços devido à nova dimensão e localização dos mercados, que passaram a atingir o âmbito mundial. A causa dessa mudança foi a aceleração do processo de globalização e a revolução tecnológica que ocorreu neste período, além da criação da União Europeia e da unificação monetária na Europa, que intensificou a internacionalização das empresas europeias.

Como a indústria da Itália está dividida em distritos industriais, há vários programas regionais que fazem referência tanto a políticas regulatórias quanto a políticas de estímulo. Normalmente, órgãos locais, como as Câmeras de Comércio (Camera di Commercio) e os Consórcios Industriais (Consorzio Industriale), são responsáveis por criar e implantar esses programas; contudo, na maioria das vezes, há parceiros privados locais ou suporte do governo.

No âmbito nacional, a Itália possui somente um programa de estímulo que poderia ser associado ao empreendedorismo, o projeto Indústria 2015 (Indústria 2015). Esse programa nacional foi lançado pelo governo italiano em 2006 com o objetivo de inserir a Itália estrategi- 
camente no atual contexto da economia internacional, além de direcionar a ação pública para continuar sustentando o desenvolvimento econômico. Esse não é um programa exclusivamente voltado paras as MPMEs, mas teoricamente deveria envolver essas empresas.

O programa visa fomentar a inovação mediante mecanismos de estímulo a parcerias entre grupos organizados do setor privado e centros de pesquisa. Basicamente, um grupo de empresas dos setores prioritários deve, em conjunto com um centro de pesquisa, apresentar um projeto que é avaliado pelo Indústria 2015.

A maior parte dos programas de estímulo na Itália é conduzida pelos governos regionais, mas são mais voltados para as MPMEs participantes dos clusters do que para um empreendedorismo gazela. Alguns exemplos desses programas estão na região Emilia-Romagna, o Programação de Negócios (Programmazione Negoziata) que busca fomentar a atividade produtiva da região por meio de normas deliberadas pela Junta Regional; apesar de estarem focadas em criação de normas, elas existem como meio de reformar o sistema industrial local. O programa tem como objetivo coordenar a interação das empresas com o sistema financeiro regional a fim de valorizar e qualificar as empresas locais. As normas criadas por esse programa buscam constituir grupos de trabalho locais para melhorar a infraestrutura do território.

Em relação às políticas regulatórias, o processo de criação de uma nova empresa na Itália não é simples devido ao grande número de documentos a serem preenchidos, como o memorando, o estatuto e o ato constitutivo. Outro fator que dificulta o ambiente empresarial são os impostos, porque as taxas mudam praticamente todo ano, sendo difícil acompanhar as mudanças. Além disso, novos impostos podem aparecer ou desaparecer a cada ano.

Outro complicador regulatório são as regras trabalhistas. Os trabalhadores são protegidos pelo Estatuto do Trabalho (Statuto dei Lavoratori) e pelo Contrato Coletivo Nacional do Trabalho (Contratto Collettivo Nazionale di Lavoro - CCNL). Esses dispositivos tornam as leis trabalhistas uma das mais rígidas da Europa. De acordo com o art. 18 do Estatuto, os trabalhadores não podem ser demitidos a não ser por justa causa. Nesse caso, a empresa deve provar que o empregado cometeu algum tipo de delito. Mesmo nesse caso é bastante difícil conseguir demitir um empregado (Bird e Berri, 2006).

Devido à burocracia no momento de abertura da empresa e aos vários tipos de tributos (nacionais e regionais) que as empresas precisam pagar, pode-se afirmar que não é fácil constituir e manter uma empresa na Itália.

\subsection{Irlanda}

Assim como no caso da Itália, a Irlanda segue a nomenclatura da Comissão Europeia de definição do porte das MPMEs.

Segundo Lundstrom e Stevenson (2001), historicamente o governo irlandês usou três diferentes estratégias para estimular o desenvolvimento econômico. Nas décadas de 1920 e 1930, a estratégia era não intervencionista e nesse período o país permaneceu industrialmente subdesenvolvido e dependente da agricultura. Entre as décadas de 1930 e 1960 
foram instituídas políticas protecionistas para estimular o desenvolvimento local. Já nas décadas de 1960 e 1970 o país passou a ser orientado para a exportação. Estas políticas acabaram resultando em pouco desenvolvimento empresarial local e alta dependência de empresas estrangeiras.

Na segunda metade da década de 1980, o cenário era de crise, com crescimento econômico inferior a 1\% ao ano e taxa de desemprego de 18\%. Em meio a essa crise foi desenvolvida uma nova estratégia focada no desenvolvimento das MPMEs e no fortalecimento dos fazendeiros. Além de políticas para a redução do déficit público, redução da inflação e privatizações, o governo reestruturou sua política fiscal de modo a atrair investimentos externos e ao mesmo tempo estimular o empreendedorismo interno.

Desde então, o governo tem assumido um papel ativo de fomento ao empreendedorismo e às MPMEs tanto no sentido da formação de clusters de classe global, quanto do estímulo ao surgimento e desenvolvimento de empresas gazelas e do foco em exportação.

Já em 1990, através do Review of Industrial Performance (Revisão do Desempenho Industrial) e, em 1992, no Culliton Report (Lundstrom e Stevenson, 2001), o governo reconhece que as políticas de estímulo ao empreendedorismo criadas a partir de 1987 não estavam gerando empresas que cresciam e tampouco criando as chamadas empresas "campeãs nacionais". Isso resultou na identificação dos principais bloqueios ao crescimento das pequenas empresas, tais como carga tributária, regras administrativas e falta de competência gerencial dos empreendedores.

A partir de então o governo irlandês vem buscando incentivar o desenvolvimento de empresas com alto potencial de crescimento e, portanto, tem sido seletivo em suas intervenções buscando identificar essas empresas gazelas. De outro lado, foi simplificada a burocracia para todas as empresas e os impostos são consideravelmente baixos; além disso, o governo passou também a desenvolver estratégias de capacitação para os empreendedores.

Toda a política pública de empreendedorismo da Irlanda está fundamentada na orientação para a exportação. Como uma economia pequena, há dentro da esfera pública claramente a visão de que a exportação é o único caminho para o crescimento do país. Esse compromisso com a abertura econômica foi fundamental para a atração de empresas multinacionais para o país e finalmente para a ocorrência do milagre celta de altas taxas de crescimento econômico na década passada.

A chave da política pública de empreendedorismo são os mecanismos em torno da criação da chamada economia inteligente (smart economy). A base da economia inteligente é o compromisso com a inovação e o fomento de um empreendedorismo indígena com alto potencial de crescimento e voltado ao mercado externo. Do lado do governo, a smart economy é alimentada pela interação de quatro agências ligadas ao Ministério das Empresas, Comércio e Inovação: Agência de Desenvolvimento Industrial (Industrial Development Agency — IDA), Fundação Irlandesa da Ciência (Science Foundation Irland - SFI), Empreendedorismo Irlandês (Enterprise Ireland - EI) e Forfás.

O papel da IDA está focado na captação de investimentos para o país especialmente para a contínua atração de empresas multinacionais. A SFI tem a missão explícita de adicionar 
valor nas cadeias de negócio por meio de pesquisa e inovação. Essa missão explícita se materializa na produção de conhecimento que pode ser absorvido tanto por multinacionais como por MPMEs. O Forfás completa as agências do Ministério provendo pesquisa independente que subsidie o governo na formulação de políticas de empreendedorismo e inovação.

Já o EI é a pedra fundamental do programa de fomento de empreendedorismo. Com o foco em empresas de alto potencial de crescimento a organização apoia o empreendedorismo por meio de: treinamento, aconselhamento e mentoring; funding geralmente buscando ao mesmo tempo desenvolver uma indústria de venture capital; fomento à P\&D criando interfaces com o trabalho desenvolvido pela SFI; e a promoção do desenvolvimento regional em parceria com Conselhos Empresariais dos Condados e Cidades (County and City Entreprise Boards - CEBs).

O Estado irlandês fez uma escolha explícita pelo empreendedor de alto potencial, limitando o apoio às MPMEs a medidas de simplificação da burocracia estatal (que já é consideravelmente simples). Portanto, essas empresas estão relegadas às forças de mercado que determinam a entrada e saída do sistema econômico.

Finalmente, cabe mencionar o papel da educação empreendedora. Além do alto nível educacional, há no país uma série de programas focados no empreendedorismo desde o ensino básico, passando pelo secundário até o terciário, muitos dos quais fomentados pelo governo. Alguns exemplos de programas são: Junior Certificate (Certificado Júnior) — organizado pelo Department of Education and Science (Ministério de Educação e Ciência), é uma disciplina no curso Enterprise on Business Studies (Empresas nos Estudos de Negócios), dado a jovens de 13 a 15 anos; Leaving Certificate Applied (LCA) — Enterprise Modules (Certificado Aplicado Vivencial — Módulos de Empreendedorismo) - organizados pelo Department of Education and Science (Departamento de Educação e Ciência), os módulos sobre educação empreendedora são obrigatórios para a obtenção do Leaving Certificate Applied.

Em relação às políticas regulatórias, pode-se salientar que são poucas em comparação às de estímulo, pois, segundo relatório do Small Business Forum (2006), não há grandes dificuldades para a entrada de novas empresas em crescimento no mercado irlandês, dado que os custos de entrada são acessíveis e não há grande resistência por parte das empresas já estabelecidas.

De acordo com o relatório do Small Business Forum (2006), ficou sob a responsabilidade do Business Regulation Forum (Fórum de Regulamentação de Negócios), fundado em 2005, o aconselhamento ao Ministério das Empresas, Comércio e Emprego quanto a regulamentações obsoletas, ineficientes ou desproporcionais.

A política regulatória mais importante com impacto direto para as MPMEs é a exigência da Avaliação de Impacto Regulatório (Regulatory Impact Analysis — RIA). Por meio desse mecanismo, toda nova legislação deve vir acompanhada da indicação de impacto para as MPMEs. Esse é um importante instrumento de desburocratização, pois obriga os diferentes agentes do Executivo e legisladores a refletirem sobre o impacto de suas propostas para as MPMEs. 


\section{Análise comparada das políticas públicas de empreendedorismo e MPMEs no Brasil, no Canadá, no Chile, na Irlanda e na Itália}

O quadro 1 resume o conjunto das políticas regulatórias observadas em cada um dos países analisados, sem contar iniciativas do nível municipal.

$$
\text { Quadro } 1
$$

Mapeamento das políticas regulatórias no Brasil, no Canadá, no Chile, na Irlanda e na Itália ${ }^{7}$

\begin{tabular}{|c|c|c|c|c|c|c|c|}
\hline & \multicolumn{7}{|c|}{ Tipo de Política Regulatória } \\
\hline & $\begin{array}{l}\text { Regras de } \\
\text { Propriedade } \\
\text { Intelectual }\end{array}$ & $\begin{array}{c}\text { Regras de } \\
\text { Falência }\end{array}$ & $\begin{array}{l}\text { Regras de } \\
\text { Entrada e } \\
\text { Saída de } \\
\text { Negócios }\end{array}$ & $\begin{array}{c}\text { Regras } \\
\text { Trabalhistas } \\
\text { e Sociais }\end{array}$ & $\begin{array}{c}\text { Regras } \\
\text { Tributárias }\end{array}$ & $\begin{array}{c}\text { Regras de } \\
\text { Propriedade }\end{array}$ & $\begin{array}{c}\text { Regras que } \\
\text { afetem a } \\
\text { liquidez e } \\
\text { disponibilidade } \\
\text { de capital }\end{array}$ \\
\hline $\begin{array}{c}\text { Nacional } \times \\
\text { Regional }\end{array}$ & $\begin{array}{l}\text { Nacional } \\
\text { Brasil (1) } \\
\text { Canadá (1) } \\
\text { Irlanda (3) }\end{array}$ & $\begin{array}{l}\text { Nacional } \\
\text { Brasil (1) } \\
\text { Canadá (2) } \\
\text { Chile (1) } \\
\text { Irlanda (1) }\end{array}$ & $\begin{array}{l}\text { Nacional } \\
\text { Brasil (1) } \\
\text { Canadá (13) } \\
\text { Chile (1) } \\
\text { Irlanda (1) }\end{array}$ & $\begin{array}{l}\text { Nacional } \\
\text { Brasil (1) } \\
\text { Canadá (5) } \\
\text { Chile (1) } \\
\text { Irlanda (1) }\end{array}$ & $\begin{array}{l}\text { Nacional } \\
\text { Brasil (1) } \\
\text { Canadá (1) } \\
\text { Chile (4) } \\
\text { Irlanda (1) }\end{array}$ & $\begin{array}{l}\text { Nacional } \\
\text { Brasil (1) } \\
\text { Canadá (1) } \\
\text { Chile (1) } \\
\text { Irlanda (2) }\end{array}$ & $\begin{array}{l}\text { Nacional } \\
\text { Canadá (1) } \\
\text { Chile (1) } \\
\text { Irlanda (1) }\end{array}$ \\
\hline $\begin{array}{l}\text { Setorial } \\
\text { Grupos }\end{array}$ & & & Canadá (4) & Canadá (1) & Brasil (8) & & \\
\hline
\end{tabular}

Fonte: Elaboração própria.

Do ponto de vista regulatório, observa-se uma grande similaridade, em quase todos os países, entre programas que sempre têm a característica de serem nacionais e focados no estímulo às MPMEs. Há algumas exceções nessa observação que chamam a atenção. Em primeiro lugar, não foram constatados programas de nível regulatório que estimulem as MPMEs na Itália; ao contrário, conforme discutido acima. Em segundo lugar, a complexidade tributária brasileira permitiu criar diversos programas de estímulo mais focados nas médias empresas, em determinados setores estratégicos. Finalmente, apesar da relativa simplicidade regulatória do Canadá, há incentivos específicos que facilitam a entrada e saída de negócios em determinados setores.

O quadro 2 resume as políticas de estímulo mapeadas nos países analisados:

${ }^{7} \mathrm{O}$ número ao lado de cada instituição indica a quantidade de políticas mapeadas na respectiva categoria. 
Quadro 2

Mapeamento das políticas de estímulo no Brasil, no Canadá, no Chile, na Itália e na Irlanda ${ }^{8}$

\begin{tabular}{|c|c|c|c|}
\hline & $\begin{array}{c}\text { Promoção de } \\
\text { cultura e educação } \\
\text { empreendedora }\end{array}$ & $\begin{array}{l}\text { Programas de } \\
\text { promoção à } \\
\text { inovação }\end{array}$ & $\begin{array}{c}\text { Programas de fomento à } \\
\text { internacionalização }\end{array}$ \\
\hline $\begin{array}{l}\text { Nacional } \\
\times \\
\text { Regional }\end{array}$ & $\begin{array}{l}\text { Nacional: } \\
\text { Canadá (9) } \\
\text { Chile (6) } \\
\text { Irlanda (9) } \\
\text { Regional: } \\
\text { Canadá (34) } \\
\text { Itália (4) } \\
\text { Irlanda (2) }\end{array}$ & $\begin{array}{l}\text { Nacional: } \\
\text { Brasil (14) } \\
\text { Canadá (2) } \\
\text { Chile (58) } \\
\text { Itália (1) } \\
\text { Irlanda (7) } \\
\text { Regional: } \\
\text { Brasil (7) } \\
\text { Canadá (3) } \\
\text { Chile (2) } \\
\text { Itália (9) } \\
\text { Irlanda (7) }\end{array}$ & $\begin{array}{l}\text { Nacional: } \\
\text { Brasil (8) } \\
\text { Canadá (1) } \\
\text { Chile (7) } \\
\text { Irlanda (4) } \\
\text { Regional: } \\
\text { Brasil (4) } \\
\text { Canadá (1) } \\
\text { Itália (2) }\end{array}$ \\
\hline Setorial & $\begin{array}{l}\text { Canadá (18) } \\
\text { Chile (1) }\end{array}$ & $\begin{array}{l}\text { Brasil (32) } \\
\text { Canadá (7) } \\
\text { Chile (18) } \\
\text { Irlanda (2) }\end{array}$ & $\begin{array}{l}\text { Brasil (11) } \\
\text { Canadá (1) } \\
\text { Chile (1) } \\
\text { Irlanda (5) }\end{array}$ \\
\hline Grupos & $\begin{array}{l}\text { Canadá (9) } \\
\text { Chile (3) } \\
\text { Itália (6) }\end{array}$ & Canadá (1) & \\
\hline
\end{tabular}

Fonte: Elaboração própria.

No Brasil, as políticas públicas se fracionam entre diversas instituições federais, estaduais e municipais, não havendo qualquer claro ponto focal dos programas. Os programas se sobrepõem entre os diversos níveis da federação, assim como no foco setorial e generalizado (sem discriminação setorial).

Entretanto, especialmente desde o estabelecimento do Estatuto das Micro e Pequenas empresas e da PITCE de 2003, observam-se mecanismos que, pela primeira vez na história do país, configurariam uma política de MPMEs. A característica central dessa política é eclosão de dezenas de programas que, em sua grande maioria, estão focados nos APLs. Ou seja, há uma

\footnotetext{
${ }^{8}$ O número ao lado de cada instituição indica a quantidade de políticas mapeadas na respectiva categoria.
} 
crença no país de que os clusters podem trazer desenvolvimento econômico ao mesmo tempo que as desigualdades regionais são diminuídas.

No caso do Chile, os programas estão centrados na Corfo. Há no país uma cultura de multiplicação de pequenos programas, todos focados no incentivo às MPMEs, não estando associada a uma visão sobre o papel dessas empresas no desenvolvimento econômico e, sim, no suporte a empreendedores estilo de vida, que, além de gerarem renda de subsistência, acabam sustentando o emprego no país. Explicitamente, estes órgãos mantêm um discurso de neutralidade regional ignorando profundas diferenças socioeconômicas nas regiões. Basicamente, a ideia é simplesmente dar maiores condições de competitividade a qualquer empresário em qualquer lugar.

Muito da política relativa às MPMEs parece ser influenciada por um laissez-faire neoliberal em que se acredita que, essencialmente, o papel do governo é a remoção de barreiras que levam a imperfeições de mercado e, de resto, a competição encarrega-se de levar o equilíbrio a esses mercados. Observa-se, portanto, no país uma política de MPMEs, mas não uma política de empreendedorismo.

A Irlanda hoje está fortemente voltada ao fomento a empreendedores de alto impacto capazes de rapidamente tornarem-se exportadores. Há no país uma forte cultura empreendedora, o que inclui diversos programas de educação empreendedora desde o ensino fundamental até as universidades. A EI é ponto focal da atual política, concentrando grande parte dos programas voltados para os potenciais empreendedores gazela. O relatório anual da Enterprise Ireland (2010) indica que, em 2009, os clientes da agência exportaram bens e serviços da ordem de U\$12,9 bilhões, incluindo U\$693 milhões em novas vendas. Esse número representa cerca de $8,5 \%$ das exportações do país, o que certamente é significativo, levando em consideração o porte das empresas envolvidas. Com a forte orientação de uma política de empreendedorismo, não se constata que haja uma política de MPMEs no país.

A Itália não tem nem nunca teve instituições em nível nacional voltadas ao fomento do empreendedorismo. Grande parte do sucesso passado dos distritos pode ser associada à cadeia de negócios envolvendo essas empresas. Esse sistema de cooperação foi quebrado à medida que a economia regional foi exposta à concorrência global. Assim, muitas empresas locais deixaram de ser competitivas e, simplesmente, desapareceram ou transferiram suas unidades produtivas para outros lugares, em especial o leste europeu e a China.

Chama a atenção na Itália o completo abandono do sul em termos de políticas públicas relacionadas às MPMEs. Parece que nem na capital e nem no norte há uma preocupação com as disparidades regionais. Ao contrário, o país vive uma discussão sobre um federalismo que acima de tudo seria fiscal. Não se observa no país uma política de empreendedorismo e as políticas para as MPMEs são regionais e bastante debilitadas.

O quadro 3 resume a incidência de políticas públicas de empreendedorismo e MPMEs nos países analisados. 
Quadro 3

\section{Quadro resumo das políticas de empreendedorismo e MPMEs no Brasil, no Canadá, no Chile e na Itália e Irlanda}

\begin{tabular}{|c|c|c|c|}
\hline País & Política de Empreendedorismo & Políticas de MPMEs & Estágio de desenvolvimento \\
\hline Brasil & Não há. & $\begin{array}{l}\text { Por meio da Lei no } 123 / 2006 \text {, o governo } \\
\text { vem buscando melhorar o ambiente } \\
\text { institucional para o empreendedor. Há } \\
\text { diversos mecanismos de apoio para as } \\
\text { MPMEs que fazem parte de APLs. }\end{array}$ & Estágio da Eficiência \\
\hline Canadá & Forte orientação via IC e NRC & $\begin{array}{l}\text { Ambiente positivo e estável já } \\
\text { estabelecido nas décadas passadas } \\
\text { exibindo estrutura institucional adequada } \\
\text { para a atividade das MPMEs. }\end{array}$ & Estágio da Inovação \\
\hline Chile & Não há & $\begin{array}{l}\text { Em processo de construção de um } \\
\text { ambiente institucional adequado para a } \\
\text { atividade das MPMEs. }\end{array}$ & $\begin{array}{l}\text { Estágio da Eficiência (em } \\
\text { transição) }\end{array}$ \\
\hline Itália & Não há & $\begin{array}{l}\text { Há poucos programas regionais que de } \\
\text { alguma forma afetam positivamente as } \\
\text { MPMEs. De modo geral, o ambiente } \\
\text { institucional dificulta a atividade das } \\
\text { MPMEs. }\end{array}$ & Estágio da Inovação \\
\hline Irlanda & $\begin{array}{l}\text { Forte orientação da política através } \\
\text { do IE }\end{array}$ & $\begin{array}{l}\text { Ambiente positivo e estável já } \\
\text { estabelecido nas décadas passadas } \\
\text { exibindo estrutura institucional adequada } \\
\text { para a atividade das MPMEs. }\end{array}$ & Estágio da Inovação \\
\hline
\end{tabular}

Fonte: Elaboração própria.

\section{Conclusões e considerações finais}

De forma geral as escolhas de política pública são compatíveis com o estágio de desenvolvimento econômico independente do tamanho do país e região, à exceção da Itália. A exceção chama atenção para algumas questões importantes: seria no caso da Itália ou talvez outros países, irrelevante a necessidade de políticas públicas de promoção ao empreendedorismo e as MPMEs? Ou, por outro lado, será que a ausência destas políticas pode a médio e longo prazo levar a Itália a regredir no estágio de desenvolvimento econômico?

Chama atenção também que, no caso do Chile, o país não tem nenhum tipo de política de empreendedorismo embora figure no GEM como um país em transição. Assim como no caso da Itália caberia perguntar, seria possível transitar para uma economia de inovação sem uma política de empreendedorismo? Usando apenas o caso da Irlanda como exemplo isso não seria possível. 
Outro ponto importante observado é que o Brasil tem uma clara escolha de apoio a APLs que raramente tendem a carregar em si empreendedores de alto impacto. Portanto cabe ainda perguntar seria a escolha de apoio a todas as APLs incompatível com uma política de empreendedorismo? Caso o Brasil aprofunde as mudanças regulatórias, seria o país capaz de transitar para a economia da inovação com uma política baseada apenas no apoio das APLs?

Outra conclusão importante é que a ideia do empreendedor gazela está presente no discurso público apenas do Canadá e da Irlanda. Aparentemente a Itália não tem mecanismo para se desenvolver dentro do estágio da inovação, o Brasil acredita no papel das grandes empresas e dos APLs como mecanismo para passar a próxima etapa enquanto no Chile o governo busca o desenvolvimento econômico através da promoção de uma economia de mercado.

As limitações deste artigo envolvem a base dos cinco países escolhidos. O estudo pode ser aprofundado cruzando o mapeamento das políticas públicas em países no mesmo estágio de desenvolvimento e com economias de porte relativamente similares.

Este artigo reviu a literatura sobre desenvolvimento econômico e políticas públicas de empreendedorismo e MPMEs e mapeou as escolhas de políticas públicas no Brasil, no Canadá, no Chile, na Irlanda e na Itália, comparando e investigando a compatibilidade das políticas e o estágio de desenvolvimento econômico. Desta forma, o artigo contribui com a literatura de empreendedorismo e políticas públicas explorando na prática as escolhas de políticas públicas e as divergências e convergências entre o modelo de estágios de desenvolvimento adotado pelo GEM/Geindex.

\section{Referências}

ÁCS, Zoltan J.; SZERB., Lázló. The global entrepreneurship index (Geindex). Foundations and Trends in Entrepreneurship, v. 5, n. 5, p. 341-435, 2009.

AUDRETSCH, David. B.; KEILBACH, Max C. Entrepreneurship capital and economic performance. Regional Studies, v. 38, p. 949-959, 2004.

BARROS, Aluízio A.; PEREIRA, Cláudia M. M. A. Empreendedorismo e crescimento econômico: uma análise empírica. Revista de Administração Contemporânea, v. 12, n. 4, 2008.

BECK, Thorsten; DEMIRGUÇ-KUNT, Asli; LEVINE, Ross. SMEs, growth and poverty. NBER Working Paper Series, 11224. Cambridge: National Bureau of Economic Research, 2005. Disponível em: <www.nber.org/papers/w11224>. Acesso em: mar. 2011.

BIRD, Emma; BERRI, Mario. Starting a business in Italy. Oxford, Reino Unido: How to Books, 2006.

DINI, Marco; STUMPO, Giovanni. Análisis de la política de fomento a las pequeñas e medianas empresas en Chile. Serie Desarrollo Productivo. Santiago de Chile, 2002. 
ENTERPRISE IRELAND. Annual report and accounts 2009. Irlanda: Enterprise Ireland, 2010.

FERRARO, Carlo; STUMPO, Giovanni. Políticas de apoyo a las pymes en América Latina. Chile: Cepal; Cooperazione Italiana, 2010.

HALL, Joshua C.; SOBEL, Russell S. Public policy and entrepreneurship. The Center for Applied Economics. The University of Kansas. Technical Report 06-0717. Jul. 2006.

HENREKSON, Magnus; JOHANSSON, Dan. Gazelles as job creators: a survey and interpretation of the evidence. IFN Working Paper $n^{\circ}$ 733, 2008.

HENREKSON, Magnus; STENKULA, Mikael. Entrepreneurship and public policy, IFN Working Paper no 804, 2009.

HOLTZ-EAKIN, Douglas; KAO, Chihwa. Entrepreneurship and economic growth: the proof is in the productivity. Center for Policy Research Working Paper No. 50. Nova York: Syracuse, 2003.

IFC. Micro, small, and medium enterprises: a collection of published data. Washington, 2007.

LUETKENHORST, Wilfried. Corporate social responsibility (CSR) and the development agenda: Should SMEs care? SME Technical Working Paper Series, 13. Viena: United Nations Industrial Development Organization, 2004.

LUNDSTROM, Anders; STEVENSON, Lois A. Entrepreneurship policy. Theory and practice. Nova York: Springer, 2005.

LUNDSTROM, Anders; STEVENSON, Lois A. On the road to entrepreneurship policy. Suécia: Swedish Foundation for Small Business Research, 2001.

MURDOCK, Karen A. Public policy for entrepreneurship and innovation: trade-offs and impacts in managed and entrepreneurial economics. Tese (doutorado) - Departamento de Economia de la Empresa, Universitat Autonoma de Barcelona, Barcelona, 2009.

NADEEM, Tariq. How to start a small business in Canada: your road map to financial freedom. Ontario: Self-Help Publishers, 2010.

NEWBERRY, Derek. The role of small and medium-sized enterprises in the futures of emerging economies. Earth trends featured topic. 2006. Disponível em: <http://earthtrends.wri.org/pdf_library/feature/eco_fea_sme.pdf>. Acesso em: jul. 2010.

OECD. Entrepreneurship at a glance 2011. Paris: OECD Publishing, 2011.

OECD. SMES, entrepreneurship and innovation. Paris: OECD Publishing, 2010.

PORTER, Michael E. et al. Executive summary: competitiveness and stages of economic development. In: PORTER, Michel et al. (Ed.). The global competitiveness report 2001-2002. Nova York: Oxford University Press. 2002. p. 16-25.

PORTER, Michael. The competitive advantage of nations. Nova York: Free Press, 1998.

RAYNARD, Peter; FORSTATER, Maya. Corporate social responsibility: implications for small and medium enterprises in developing countries. Viena: United Nations Industrial Development Organization, 2002. 
RIVERIN, Nathaly et al. Global entrepreneurship monitor: the Canadian report. Montreal: Economic Development; HEC Montreal; Sauder School of Business; W. Maurice Youg, 2003.

SMALL BUSINESS FORUM. Small business is big business. Dublin: Small Business Forum, 2006.

STEVENSON, Lois A.; LUNDSTROM, Anders. Patterns and trends in entrepreneurship/SME policy and practice in ten economies. Orebro: Swedish Foundation for Small Business, 2001.

STOREY, David J. Entrepreneurship and society. In: WORLD ENTREPRENEURSHIP FORUM, 2008, Evian.

VAN STEL, Andre; CARREE, Martin; THURIK, Roy. The effect of entrepreneurial activity on national economic growth. Small Business Economics, v. 24, n. 3, p. 311-321, 2005.

WENNEKERS, Sander; THURIK, Roy. Linking entrepreneurship and economic growth. Small Business Economics, v. 13, n. 1, p. 27-55, 1999.

Gilberto Sarfati fez pós-doutorado em estratégia empresarial na Escola de Administração de Empresas de São Paulo da Fundação Getulio Vargas (FGV-EAESP) e é doutor em relações internacionais pela Universidade de São Paulo (USP). É professor do Departamento de Administração e Recursos Humanos da FGV-EAESP. E-mail: gilberto.sarfati@fgv.br. 